\section{Treatment of Syringomyelia}

A technique devised by himself enabled Benedict Stilling (1810-1879) to cut serial sections of the spinal cord after preliminary hardening in alcohol. "We found a round opening, the canalis spinalis"-a hitherto unknown anatomical entity. ${ }^{1}$ Pathological cavitation of the cord had been previously described under the name of syringomyelia. ${ }^{2}$ This term later came to be reserved for those cystic conditions of the cord which were independent of the central canal, whereas distension of the central canal by fluid was called hydromyelia. ${ }^{3}$

The clear-cut distinction between these two pathological conditions implied in this terminology continued to be made until the formulation by W. J. Gardner in 1957 of his "hydrodynamic theory" of the genesis of syringomyelia." In the embryo the central canal and the ventricular system form a single closed structure. When later, by the formation of the large foramen of Magendie, the ventricular fluid becomes diverted into the subarachnoid space, the central canal acquires its eventual vestigial form. Gardner examined the possible consequences of stenosis of the foramen of Magendie of such a degree as to allow the flow of ventricular fluid at the rate it is being formed yct preclude sudden displacements of ventricular fluid during the cardiac systole. He argued that the fluid pulse wave thus confined will be funnelled into the upper end of the central canal, and concluded that over the years this abnormal hydrodynamic force would cause a very gradual dilatation of the central canal. By virtue of the reinforcement conferred by the interlacing fibres of decussation, the upper part of the canal might be expected to resist this force. Equally, distance would afford to the caudal part of the canal a similar protection against the hydraulic hammer effect. These factors would account for the fact that pathological changes in syringomyelia are most frequently situated in the lower cervical and upper thoracic regions of the cord.

A tiny rupture of the ependymal lining of the central canal will permit the fluid to dissect a true syrinx in the posterior horns and in the long tracts paralleling the hydromyelic cavity. The resulting fistulous tracks, intercommunicating or detached, might extend upwards into the pons.

The hydrodynamic theory hinges on the incompetence of the foramen of Magendie either through faulty development or as result of mechanical obstruction. This basic tenet of the theory was fully corroborated by Gardner's finding that the foramen of Magendie was in varying degree obstructed in all his 74 cases of syringomyelia. In $92 \%$ of his cases this was due to a Chiari malformation. The latter in the adult is characterized by a caudal displacement of the cerebellar tonsils through the foramen magnum, as a rule without associated bony spinal malformations.

Gardner's findings are in close agreement with those given recently by British neurosurgeons who have also described chronic arachnoiditis adjacent to the fourth ventricle and foramen magnum in a few cases of syringomyelia. ${ }^{5-8}$ Arachnoiditis in the same situation may perhaps explain the rare cases of late cervical syringomyelia after injuries to the dorsal and lumbar spinal cord. ${ }^{9,}, 10 \mathrm{~A}$ corollary of the hydrodynamic theory is that the cavities are in direct communication with the central canal. This has now been demonstrated by a variety of methods, the most conclusive of which involves the injection of radio-iodinated human serum albumin into a syrinx. The isotope can be detected in the cisterns of the brain within a few hours. ${ }^{11}$ Syrinx fluid obtained by aspiration has all the characteristics of cerebrospinal fluid. ${ }^{6}$
Intraspinal neoplasms have been found in some $20 \%$ of syringomyelic cords. According to Gardner syringomyelia in the adult is due to failure of the rhombic roof to become adequately permeable at the critical stage in embryonic life when cerebrospinal fluid is secreted in increasing amounts. He therefore suggested that the frequent association of tumours with syringomyelia could be due to heterotopia resulting from pressure distortion of the embryonic neural tube. ${ }^{4}$ However, the most important implication of the hydrodynamic theory is the basis it offers for treatment. According to Gardner "proper surgical treatment of syringomyelia consists in dissecting open the foramen of Magendie". 5 Owing to the irreversible changes in the spinal cord, operation on the hindbrain can only arrest the disease process or at most bring about some amelioration of existing signs and symptoms in some cases. These conclusions are borne out by the postoperative results. ${ }^{5-7}$ In some cases it may well be better to undertake ventricular drainage, since this may be expected to reduce the systolic pressure waves in the ventricular fluid. ${ }^{8}$

Syringomyelia has been treated by radiotherapy since 1905 , and V. Logue 7 has recently reviewed the published results. $\mathrm{He}$ noted in this field "an extreme divergence of views and practice between the Continent and this country". The subjective nature of the improvement, usually against the background of a static or deteriorating neurological picture, may help to explain the want of enthusiasm for this treatment. ${ }^{7}$ We do not know enough of the natural history of syringomyelia to evaluate the efficacy of treatments.

Harvey Cushing said of Homo chirurgicus that "he who formerly was content to nibble at, and occasionally to lop off the external parts of the body under the direction of Homo medicus internus has gradually become more internal than $\mathrm{H}$. internus himself. He soon began peering into holes that had neither windows nor shutters and learned much as he went along that was new and unrecorded".12 The hydrodynamic mechanism of syringomyelia is one such discovery.

\footnotetext{
'Stilling, B., and Wallach, J., Untersuchungen überd die Textur des Rückenmarks. Leipzig, Wigand, 1842.

${ }^{2}$ Ollivier, C. P., Traité de la Moelle épinière et de ses Maladies, 2nd edn. Paris, Crevot, 1827.

Simon, T., Archiv für Psychiatrie und Nervenkrankheiten, 1875, 5, 120

- Gardner, W. J., Karnosh, L. J., and Angel, J., Transactions of the Americal Neurological Association, 1957, 82, 144 .

Neurological Association, $1957,82,144$.
Gardner, W. J., Fournal of Neurology, Neurosurgery and Psychiatry, 1965, 28, 247

${ }^{6}$ Newton, E. J., Annals of the Royal College of Surgeons of England, 1969, 44,

' Logue, V., Clinical Radiology, 1971, 22, 2.

${ }^{8}$ Appleby, A., Bradley, W. G., Foster, J. B., Hankinson, J., and Hudson, P., Fournal of the Neurological Sciences, 1969, 8. 451.

Barnett, H. J. M., Botterell, E. H., Jousse, A. T., and Wynn-Jones, M., Brain, 1966, 89, 159.

"Rossier, A. B., Werner, A., Wildi, E., and Berney, J., fournal of Neurology, Neurosurgery and Psychiatry, 1968, 31, 99.

1 Ellertsson, A. B., and Greitz, T., Acta Neurologica Scandinavica, 1969, 45, 418.

${ }^{12}$ Cushing, H., New England fournal of Medicine, 1933, 208, 922.
}

\section{Osteosarcoma}

Osteosarcoma kills four out of five of its victims within two years of onset. Most of these are under 20. The highest incidence is around the knee, and it is, therefore, not surprising that primary amputation-the original treatmentis still advised. With the availability of modern radiotherapeutic methods, is such a mutilating operation, particularly in a child, still justified?

The report of the Medical Research Council's Working Party on Bone Sarcoma, which is published at p. 363, goes 
some way towards answering this question by its careful retrospective analysis of 469 primary tumours of bone. By the very nature of the study and the rarity of the tumour many questions are left unanswered. For the first time however, a iarge number of patients with undoubted osteosarcoma treated in different ways have been subjected to critical analysis. The results, though marred by uncertain factors of selection and not approaching a clinical trial, will be of some help to those responsible for the management of these unfortunate children.

Nowadays most patients in Britain are treated either by primary amputation-about one third-or by a method similar to that advocated by Sir Stanford Cade.' This requires all patients to have radiotherapy as the initial treatment, and reserves amputation only for those whose growth fails to respond or for those more fortunate ones with a reasonable chance of survival in whom no pulmonary metastases are present four to five months after treatment. In this way, about half are spared what, in retrospect, will prove to be an unnecessary amputation.

There are possible disadvantages of this latter method. Firstly, some patients spared amputation because of the early development of metastases might later suffer considerable pain from the effects of late local recurrence. Unfortunately, this doubt cannot be resolved, for there is no reliable information on the incidence of such complications, which if high would be a strong argument in favour of primary amputation. The second theoretical disadvantage of Cade's method is that during the "waiting period" after radiotherapy apparently viable tumour cells-that have been shown to survive in at least one in three primary growths after a full course of radiotherapy-might themselves metastasize. This possibility cannot be denied; but, in spite of it, the working party's findings are that patients treated by primary amputation fared no better in terms of survival than the other group in which all had radiotherapy but where many were spared amputation.

Leaving aside future developments under trial such as chemotherapy, which has shown little promise in osteosarcoma, and the theoretical possibilities of immunotherapy, what then should be the management of a patient with osteosarcoma today? Biopsy is essential and there is no evidence that it is harmful. With the diagnosis established, a full course of radiotherapy should be given. Those patients whose local clinical and radiological response to irradiation is unsatisfactory require amputation. The remainder should be reviewed four to five months later, when about threequarters of those who will die will have already developed their pulmonary metastases, and those whose lungs remain clear will have a good chance of survival. It is this last group of patients who then complete their treatment by amputation at a level above that of the bone involved.

Relief of suffering for those who will die is ensured for most by the initial radiotherapy, but in some also by the ready acceptance of the necessity for late palliative amputation should the need arise. The surgeon should not hesitate to amputate early when signs of recurrence develop if death is not close. At all costs the child must be spared the horror of painful local recurrence, perhaps with pathological fracture or even fungation. Finally there must be close surveillance of those free from pulmonary metastases, in order that the rare opportunity for successful resection of a solitary deposit in the lung is not missed.

Until some better form of treatment emerges, the management of a patient with osteosarcoma must be shared be- tween radiotherapist and surgeon. Their aim is cure. Howcver, for the 80 " who will, in spite of this treatment, dic of their disease, palliation will prove to be a most worthwhile result.

Cade S., British fournal of Radiology, 1947, 20, 10

\section{Disease and Technology}

Just as the health of an individual depends partly on the way he lives and not simply on the aid he gets from such outside agencies as his family doctor or hospital consultant, so with the health of communities and countries. Whatever their stage of development, all countries are exchanging information and staff, offering educational facilities and permanent employment, in the unending battle against disease. That well-developed countries should help the less technically advanced is an obligation generally agreed regardless of mere self-interest, but whethe : these well-off nations should accept so unquestioningly the services of doctors and nurses from the poorer parts of the world may be doubted. For once again the DirectoGeneral of the World Health Organization, Dr. M. G. Candau,' has drawn attention to the "grave lack of health manpower, especially in the developing countrics, which tragically retards world progress towards better health." While outside technical aid is still indispensible for many countries-and they themselves gratefully acknowledge itthe building up of their own health services is the outstanding challenge of the 1970s. The sanitary reforms that greatly improved health in Britain during the second half of the nineteenth century have still to get under way in many developing countries-or for that matter to make their full impact on parts of the Mediterranean littoral.

Unfortunately technical advancement is helping to spread diseases as well as to prevent them. Air journeys much shorter than the incubation periods of most diseases are now recognized to be a hazard we must learn to live with, and public health services are having to adapt themselves accordingly. The risks of returning to Britain with latent malaria or typhoid fever are perhaps becoming more generally known. Increasing travel to the tropics will certainly mean greater exposure to diseases less familiar in this country, among them cholera. One case was diagnosed in Britain last year in a man who returned from holiday in Tunisia,? and the first recorded spread of the disease to Africa south of the Sahara in the same year was, as Dr. Candau says, the public health event of the year. It underlines the lesson he draws: countries must provide adequate sanitation and develop the basic health and laboratory services that are fundamental to attainment and maintenance of health.

The relentless advance of bilharzia in Africa in the wake of water supplies for irrigation is another worrying result of applied technology. But a third unhealthy byproduct of man's technical activities, air pollution, is essentially a problem for the industrialized countries, though its ill effects certainly spread far beyond their boundaries. A step towards its measurement and eventual control was the establishment last year of an international monitoring network under the W.H.O. It is the first practical attempt to study the matter on a world scale.

1 Official Records of the World Health Organizaticn, No. 188, The 2 British Medical fournal, 1970, 4, 2, 61 . 